\title{
The impact of heterogeneous surface temperatures on the 2-m air temperature over the Arctic Ocean under clear skies in spring
}

\author{
A. Tetzlaff ${ }^{1,2}$, L. Kaleschke ${ }^{1}$, C. Lüpkes ${ }^{2}$, F. Ament ${ }^{3}$, and T. Vihma ${ }^{4}$ \\ ${ }^{1}$ Institute of Oceanography, University of Hamburg, Germany \\ ${ }^{2}$ Alfred Wegener Institute for Polar and Marine Research, Bremerhaven, Germany \\ ${ }^{3}$ Institute of Meteorology, University of Hamburg, Germany \\ ${ }^{4}$ Finnish Meteorological Institute, Helsinki, Finland
}

Correspondence to: A. Tetzlaff (amelie.tetzlaff@awi.de)

Received: 3 July 2012 - Published in The Cryosphere Discuss.: 31 July 2012

Revised: 21 December 2012 - Accepted: 9 January 2013 - Published: 30 January 2013

\begin{abstract}
The influence of spatial surface temperature changes over the Arctic Ocean on the 2-m air temperature variability is estimated using backward trajectories based on ERA-Interim and JRA25 wind fields. They are initiated at Alert, Barrow and at the Tara drifting station. Three different methods are used. The first one compares mean ice surface temperatures along the trajectories to the observed 2-m air temperatures at the stations. The second one correlates the observed temperatures to air temperatures obtained using a simple Lagrangian box model that only includes the effect of sensible heat fluxes. For the third method, mean sensible heat fluxes from the model are correlated with the difference of the air temperatures at the model starting point and the observed temperatures at the stations. The calculations are based on MODIS ice surface temperatures and four different sets of ice concentration derived from SSM/I (Special Sensor Microwave Imager) and AMSR-E (Advanced Microwave Scanning Radiometer for EOS) data. Under nearly cloud-free conditions, up to $90 \%$ of the 2-m air temperature variance can be explained for Alert, and $70 \%$ for Barrow, using these methods. The differences are attributed to the different ice conditions, which are characterized by high ice concentration around Alert and lower ice concentration near Barrow. These results are robust for the different sets of reanalyses and ice concentration data. Trajectories based on 10-m wind fields from both reanalyses show large spatial differences in the Central Arctic, leading to differences in the correlations between modeled and observed 2-m air temperatures. They are most pronounced at Tara, where explained variances amount to $70 \%$ using JRA and $80 \%$ using ERA. The results also
\end{abstract}

suggest that near-surface temperatures at a given site are influenced by the variability of surface temperatures in a domain of about $200 \mathrm{~km}$ radius around the site.

\section{Introduction}

Sea ice plays an important role in the climate system. It insulates the ocean from the atmosphere and thus hampers the exchange of gases, moisture and heat. The strength of the insulation effect depends, however, on the sea ice thickness and sea ice concentration. Openings in sea ice act as windows and allow a direct ocean-atmosphere interaction, with a large impact on the surface energy budget of the polar ocean and atmosphere. In order to obtain accurate fluxes, which determine the energy budgets, the sea ice concentration should be well represented in climate and weather prediction models. Also for reanalyses, a correct representation of ice concentrations is crucial for heat flux calculations (Inoue et al., 2011).

In this context the importance of accurate ice concentration measurements becomes apparent. Using remote sensing data from the Special Sensor Microwave Imager (SSM/I), uncertainties of at least $4 \%$ arise for different algorithms in regions with high ice concentrations such as the Central Arctic (Andersen et al., 2007). Furthermore, Inoue et al. (2008) found an underestimation of the Advanced Microwave Scanning Radiometer for EOS (AMSR-E) ice concentration of $7 \%$ due to meltponds.

Several modeling studies have revealed a high sensitivity of atmospheric boundary layer temperatures to the ice 
cover. Lüpkes et al. (2008) used a one-dimensional atmospheric model coupled with a sea ice model to investigate the influence of a change in ice cover on the atmospheric boundary layer temperatures. They found that, under clear skies in winter and for ice concentrations close to $100 \%$, a change in ice concentration of $1 \%$ can cause a change of the near-surface equilibrium temperature by up to $3.5 \mathrm{~K}$ after 2 days of development. Valkonen et al. (2008) have shown that during a cold-air outbreak in the Antarctic sea ice zone, the modeled $2-\mathrm{m}$ air temperature varied by up to $13 \mathrm{~K}$, depending on the algorithm applied to derive the sea ice concentration. Parkinson et al. (2001) found that uncertainties in total ice concentrations of $\pm 7 \%$ can cause local temperature changes exceeding $6 \mathrm{~K}$ in polar regions and changes in global annual mean temperatures of about $0.3 \mathrm{~K}$, using a global climate model.

Leads represent a large source of surface temperature variability. Different characteristics of their impact on the atmospheric boundary layer have been measured, such as the annual cycle of sensible heat fluxes (Persson et al., 1992), the development of sensible heat fluxes on the downwind side of leads (Ruffieux et al., 1995), and different convection regimes over leads (Andreas and Cash, 1999). Heat fluxes over ice and open water areas have also been obtained from aircraft measurements (Fiedler et al., 2010) and have been estimated using surface temperatures from the Advanced Very High Resolution Radiometer (AVHRR) (Meier et al., 1997; Overland et al., 2000). Heat and moisture fluxes from polynyas have been estimated using data from SSM/I (Martin et al., 2004) and AMSR-E (Boisvert et al., 2012).

The goal of the present study is to supplement the abovementioned studies on the impact of sea ice variability by studying the impact of spatial surface temperature variability on the air temperature at a given location. For this purpose, backward trajectories arriving at three stations in the Arctic are calculated from reanalysis data. Ice concentrations and ice surface temperatures along the trajectories are prescribed from satellite data. The mean ice surface temperature along the trajectories, as well as the air temperature and sensible heat fluxes obtained by a simple Lagrangian box model, are then compared to the 2-m air temperatures measured at the stations.

The application of these methods aims to obtain answers to the following questions: how important are spatial changes in surface temperatures in the high ice concentration regime for local atmospheric temperature changes? To what spatial extent do heterogeneous surface temperatures influence the air temperature variability? How strong do the results depend on the choice of different reanalyses for the calculation of trajectories and on different sea ice concentration products?

A description of the data is given in Sect. 2 and the methods are described in Sect. 3. The results are presented in Sect. 4, followed by a discussion (Sect. 5) and conclusions (Sect. 6).

\section{Data}

For the present study, hourly 2-m air temperatures from three different stations in the Arctic are used. The first two stations are Barrow (Alaska) and Alert (Canada) (Fig. 1). Only the coldest months with the largest ice extent are used. For the present analysis, these are February and March for Barrow (2003-2008) and February through April for Alert (20032006). These two stations are supplemented by temperatures measured from the French schooner Tara, which drifted through the Central Arctic in 2006-2007 during a campaign that was part of the project DAMOCLES (Developing Arctic Modeling and Observing Capabilities for Long-term Environmental Studies) (Vihma et al., 2008). As the thermal differences between sea ice and open water surfaces are small in summer, only one month (April 2007) of Tara data was used in the analysis. Despite the short time series, Tara provides invaluable data since measurements from the Central Arctic are sparse.

Backward trajectories arriving at the stations are calculated from the $10 \mathrm{~m}$-wind fields of the Japanese $25-\mathrm{yr}$ reanalysis (JRA) (Onogi et al., 2007) and of the European Centre for Medium-Range Weather Forecasts (ECMWF) reanalysis (ERA-Interim) (Dee et al., 2011). Both reanalyses are available every $6 \mathrm{~h}$ with a resolution of 1.125 and $1.5^{\circ}$ (and $0.75^{\circ}$ ) for JRA and ERA, respectively. Sea level pressure fields from both reanalyses are used to calculate potential temperatures. The ERA forecast runs also provide boundary layer depths every $3 \mathrm{~h}$.

The Lagrangian box model following the trajectories requires ice concentration and ice surface temperature as input data. Four different ice concentration data sets are used. These are the SSM/I data with a resolution of $12.5 \mathrm{~km}$ (Kaleschke et al., 2001) and AMSR-E data with a resolution of $6.25 \mathrm{~km}$ (Spreen et al., 2008) starting in June 2002. Both ice concentrations are derived using the ARTIST sea ice (ASI) algorithm (Kaleschke et al., 2001) and are available through the CliSAP-Integrated Climate Data Center (ICDC). In addition, ice concentrations from AMSR-E using the NASA Team 2 (NT2) and the Bootstrap algorithm are used (Cavalieri et al., 2004). Both have a grid spacing of $12.5 \mathrm{~km}$ and are provided by NSIDC. Abbreviations for the different combinations of reanalyses and ice concentration data are given in Table 1 and are labeled as a sequence of reanalysis, sensor and algorithm.

Sea ice surface temperatures are obtained from the MOD29 (MODIS/Terra Sea Ice Extent and IST Daily L3 Global 4 km EASE-Grid Day) data set by Hall et al. (2006). Data have been available since 24 February 2000 with a resolution of $4 \mathrm{~km}$. They are aggregated to a $12.5 \mathrm{~km}$ grid. The measured MOD29 temperature, however, represents the surface temperature of a whole pixel and is also influenced by open water areas in that pixel. Therefore, the MOD29 surface temperatures are linearly weighted using the ice concentration products to obtain a better estimate of the actual 
Table 1. Abbreviations used for the different combinations of reanalyses and ice concentration data sets.

\begin{tabular}{llll}
\hline Reanalysis & Sensor & Algorithm & Abbreviation \\
\hline JRA & SSM/I & ASI & JSA \\
JRA & AMSR-E & ASI & JAA \\
JRA & AMSR-E & NASA Team 2 & JAN \\
JRA & AMSR-E & Bootstrap & JAB \\
ERA & SSM/I & ASI & ESA \\
ERA & AMSR-E & ASI & EAA \\
ERA & AMSR-E & NASA Team 2 & EAN \\
ERA & AMSR-E & Bootstrap & EAB \\
\hline
\end{tabular}

ice surface temperatures. MOD29 data contain gaps, mainly due to clouds. Considering all trajectories over ice, there are $8 \%$ missing values for Barrow, $20 \%$ for Alert and $32 \%$ for Tara. Since positive cloud radiative forcing changes ice surface temperatures considerably, only trajectories without data gaps are considered. However, this constraint leaves too few considered cases for Tara, and hence cases with less than $10 \%$ missing values are also allowed. Here, the missing values are replaced using a linear interpolation along the trajectory.

\section{Methods}

\subsection{Backward trajectories}

Two-dimensional trajectories are calculated based on the $10 \mathrm{~m}$-wind fields of the JRA and ERA reanalyses. A time step of $1 \mathrm{~h}$ is used for the calculation, and the velocity at a certain point is obtained by linearly weighting the wind velocities of the surrounding four points according to their distance in spherical coordinates. Only those trajectories are considered that do not pass over land along their path.

\subsection{Statistical analysis method}

The influence of surface temperatures along the trajectories on atmospheric boundary layer temperatures is examined using three different methods. As a first approach, the mean ice surface temperatures along the trajectories are compared to the in situ 2-m air temperatures at the stations (IST method) by calculating correlation coefficients $r$, root mean squared errors (RMSE) and biases. This approach does not account for the impact of the spatial surface temperature variability along one trajectory. However, the spatial variability of the ice surface temperatures between trajectories with different paths is accounted for. Since the MOD29 ice surface temperatures are given as daily fields, the observed variability during one day is only due to spatial differences caused by different trajectory paths and not due to temporal changes of the ice surface temperature. For time periods longer than one day, there is also the day-to-day variability of the ice surface temperatures. It can be shown by a simple statistical analysis that the impact of this variability on correlation coefficients is small compared with the spatial variability caused by different trajectory paths.

The second approach includes the influence of the spatial surface temperature variability along each trajectory by its impact on the air temperature evolution along the trajectories, which is calculated using a simple box model (Sect. 3.3). In the following, this method is called the air temperature method (AT). Air temperature changes are only caused by sensible heat fluxes from ice or open water areas and by radiative cooling in the model. The squared correlation coefficient between the modeled and the observed 2-m air temperature at the stations gives the amount of air temperature variability explained by the model, i.e., by changes in surface sensible heat fluxes. The spatial extent at which surface temperature changes are important for air temperature variability is then the radius of impact. It is determined by analyzing the changes of the explained variances as a function of the trajectory length.

Another possibility to get information about the radius of impact can be based on the investigation of the temperature changes along trajectories caused by heat fluxes. In this third approach, the differences between the observed temperatures at the trajectory starting and ending points (the latter are Barrow, Alert and Tara) are correlated with the mean sensible heat fluxes along the trajectories. As a first guess, the air temperature at the trajectory starting point is assumed to equal the ice surface temperature. In the following, this method is called the temperature variability method (TV). The sensible heat fluxes are obtained from the same simple box model as used for the AT method. Results of IST and AT are presented in Sect. 4.4, while TV results are added in Sect. 4.5 only.

For all methods, $95 \%$ confidence intervals for the correlations are obtained using a Fisher's z-transformation (von Storch and Zwiers, 1999). In addition, biases and root mean squared error values (RMSE) between the temperatures are calculated. The significance of these values can be tested using a Student's t-test (von Storch and Zwiers, 1999). These significance tests require the degrees of freedom. Since hourly temperature measurements are not statistically independent, the degrees of freedom are not equal to the number of observations. Therefore, lag correlations of the in situ temperatures are calculated. The time, where the $95 \%$ confidence interval of the lag correlation reaches $1 / e$, gives the time scale at which observations become independent. These are $27 \mathrm{~h}$ for Barrow, $23 \mathrm{~h}$ for Alert and $10 \mathrm{~h}$ for Tara. The length of the time series is reduced to the effective length, and the degrees of freedom are reduced, using these time scales.

\subsection{Box model}

For the AT and TV methods, a simple box model is used to investigate the Lagrangian change of air temperatures along trajectories. The dominant source term in the prognostic 
equation for potential temperature is assumed to be the turbulent sensible heat flux at the surface. Radiative cooling of the air column is also accounted for by assuming a constant cooling rate $c$ of $2^{\circ} \mathrm{C}$ per day, as in Vihma et al. (2003). Contributions from other processes such as condensation or cloud radiative effects are only indirectly taken into account by their impact on the surface temperature, which is prescribed from observations. Therefore, the balance equation of temperature becomes

$$
\frac{\mathrm{d} \theta(z)}{\mathrm{d} t}=-\frac{\partial \overline{w^{\prime} \theta^{\prime}}(z)}{\partial z}-c \cdot \exp \left(-\frac{z}{z_{\mathrm{c}}}\right),
$$

where $\theta$ is the potential temperature of the air, $\overline{w^{\prime} \theta^{\prime}}$ is the turbulent sensible heat flux, and the height $z_{\mathrm{c}}$ is $600 \mathrm{~m}$. Equation (1) is integrated over the boundary layer (BL) height $H$, which is represented as a box of constant height in the Lagrangian model. The box travels along a trajectory calculated from reanalysis data (Sect. 3.1).

In general, the solution to Eq. (1) depends on the specified temperature profile. However, it can be shown (Appendix A) that the solutions are identical for a well-mixed BL with height constant $\theta$ and for a more general power law temperature profile. This holds for the assumption that both the difference between the temperatures at $10 \mathrm{~m}$ height and at the BL top and the mixed layer height $H$ are not dependent on time. In the following, however, a well-mixed $\mathrm{BL}$ is assumed, since in this case the latter condition ( $H=$ const.) is not necessary. Furthermore, a constant flux layer is assumed below the reference height of $z_{\text {ref }}=10 \mathrm{~m}$, with logarithmic profiles of wind and potential temperature.

To verify the assumption of a well-mixed BL, radiosonde data are analyzed. Since soundings at Tara during the considered period are sparse and the soundings at Alert are conducted at higher elevations than the temperature measurements, only data from Barrow are considered. Soundings from the University of Wyoming data set are used, which are available every $12 \mathrm{~h}$. Only those soundings with wind direction from the ice are considered. The stratification is expressed in terms of the Richardson number $(R i)$ in the lowest $30 \mathrm{~m}$ as a function of wind speed (Fig. 2). For wind speeds between 2 and $4 \mathrm{~m} \mathrm{~s}^{-1}$, about $90 \%$ of the $R i$ numbers are below the critical value of 0.25 and $75 \%$ below 0.1 . Therefore, the assumption of a well-mixed BL seems to be valid for wind speeds above $3 \mathrm{~m} \mathrm{~s}^{-1}$. In addition, the few soundings from Tara all show a well mixed BL. Therefore, only trajectories with $90 \%$ of the wind speeds above $3 \mathrm{~m} \mathrm{~s}^{-1}$ are considered. This limit is lowered to $80 \%$ of the wind speed above $2 \mathrm{~m} \mathrm{~s}^{-1}$ for Alert, since too few cases remain if the stricter criterion is applied.
The fluxes of sensible heat over ice and water are expressed as bulk formulations and weighted with the ice concentration so that the temperature evolution is calculated as follows:

$$
\begin{gathered}
\left(H-z_{\mathrm{ref}}\right) \frac{\mathrm{d} \theta_{\mathrm{a}}}{\mathrm{d} t}=c \cdot z_{\mathrm{c}} \cdot\left(\exp \left(-\frac{H}{z_{\mathrm{c}}}\right)-\exp \left(-\frac{z_{\mathrm{ref}}}{z_{\mathrm{c}}}\right)\right) \\
+A|\boldsymbol{u}| C_{\mathrm{si}}\left(\theta_{\mathrm{i}}-\theta_{\mathrm{a}}\right)+(1-A)|\boldsymbol{u}| C_{\mathrm{sw}}\left(\theta_{\mathrm{w}}-\theta_{\mathrm{a}}\right),
\end{gathered}
$$

where $\theta_{\mathrm{i}}, \theta_{\mathrm{w}}$ and $\theta_{\mathrm{a}}$ are the potential temperatures of ice, water and air, respectively. $A$ is the ice concentration and $|\boldsymbol{u}|$ is the wind speed at $z_{\text {ref }}=10 \mathrm{~m}$. The solution to Eq. (2) is based on an explicit Eulerian numerical scheme with a relatively large time step $\Delta t$ of $15 \mathrm{~min}$. However, for moderate wind speeds a reduction to $1 \mathrm{~min}$ caused changes in the order of $0.2^{\circ} \mathrm{C}$ only, so this impact is negligible compared to other uncertainties. The water temperature $T_{\mathrm{w}}$ is permanently at the freezing point of $-1.9^{\circ} \mathrm{C} . C_{\mathrm{si}}$ and $C_{\mathrm{sw}}$ are the heat transfer coefficients for ice and water, respectively. They are calculated using the Monin-Obukhov similarity theory:

$C_{\mathrm{S}}=\frac{\kappa^{2}}{\left(\ln \left(\frac{z}{z_{0}}\right)-\Psi_{\mathrm{m}}\left(\frac{z}{L}\right)\right)\left(\ln \left(\frac{z}{z_{T}}\right)-\Psi_{\mathrm{h}}\left(\frac{z}{L}\right)\right)}$,

where $L$ is the Obukhov length, $\kappa$ is the von Kármán constant, and the $\Psi$-functions for momentum and heat are chosen according to Grachev et al. (2007). The surface roughness lengths $z_{0}$ are assumed to be constant with values of $1 \mathrm{~mm}$ for ice and $0.1 \mathrm{~mm}$ for water (as often used, for example by Lüpkes et al., 2008) and the roughness lengths for heat $z_{T}$ are one tenth of it, respectively. $L$ is calculated iteratively using

$L=\frac{u_{*}^{2} \bar{\theta}}{\kappa g \theta_{*}}$,

which neglects the influence of humidity. It is inserted into the turbulent scaling parameters for temperature and velocity:

$\theta_{*}=\kappa\left(\theta(z)-\theta_{\mathrm{s}}\right)\left(\ln \left(\frac{z}{z_{T}}\right)-\Psi_{h}\left(\frac{z}{L}\right)\right)^{-1}$

$u_{*}=\kappa|\boldsymbol{u}|\left(\ln \left(\frac{z}{z_{0}}\right)-\Psi_{m}\left(\frac{z}{L}\right)\right)^{-1}$,

after Pielke (2002), which are then used to obtain new values of $L . \bar{\theta}$ is the mean potential temperature of the air.

The transfer coefficients are calculated for the reference height of $z_{\text {ref }}=10 \mathrm{~m}$. For comparison with the in situ 2-m air temperatures, the potential temperatures are reduced to a height of $2 \mathrm{~m}$, assuming a logarithmic temperature profile below $10 \mathrm{~m}$. Air temperatures are then obtained from the $2 \mathrm{~m}$ potential temperatures using the sea level pressure from the reanalysis.

Two different approaches are used for the boundary layer depth. In the first approach it is set to a constant value. Two 


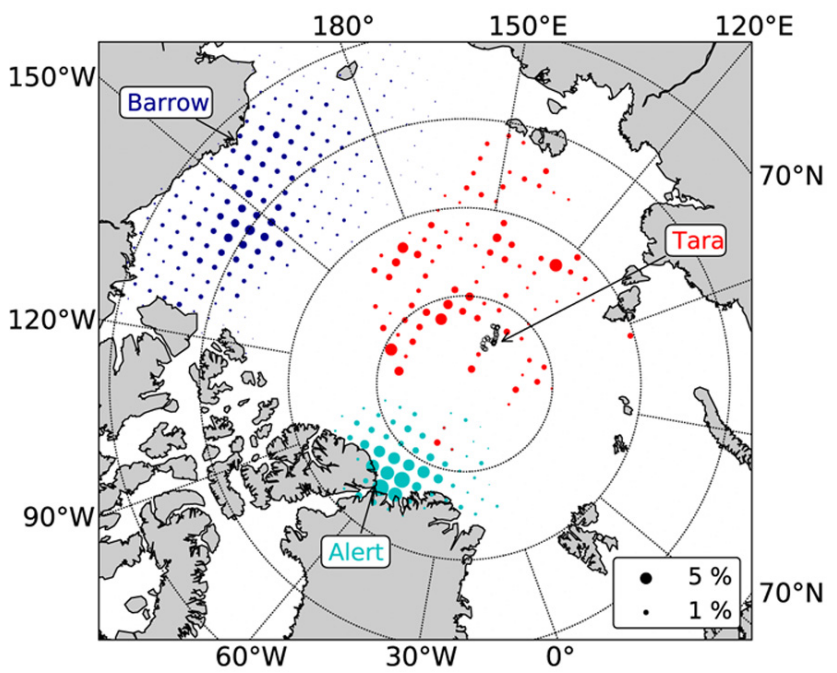

Fig. 1. Distribution of the trajectory starting points upwind of Alert (light blue), Barrow (dark blue) and Tara (red) for JRA and ERA combined. The grid cell size is $100 \mathrm{~km}$ and the size of the circles indicates the relative frequency. The arrows mark the in situ stations and the Tara drift track in April 2007.

different values are applied that are typical for the Arctic BL (Lüpkes et al., 2012b). The first one, $350 \mathrm{~m}$, was, for example, measured over a flaw lead polynya in the Canadian Archipelago by Raddatz et al. (2011). The second one, $100 \mathrm{~m}$, is close to often observed values (reported e.g. by Tjernström and Graversen (2009) for the SHEBA project north of Alaska, by Hartmann et al. (1997) for the marginal ice zone and by Lüpkes et al. (2010) for the inner Arctic Ocean). Using larger BL depths would increase the e-folding time (see below) and the model output temperatures would not differ much from the initial temperatures. There were also more than $25 \%$ surface-based inversions in February and March during SHEBA. However, during the cold seasons, leads and polynyas that are passed by the trajectories cause vertical mixing due to convection and thus a deepening of the boundary layer. Therefore, no constant BL depth smaller than $100 \mathrm{~m}$ is used.

As a second approach, BL depths are taken from the ERAInterim 3-hourly forecast runs. Values from the four closest points are linearly interpolated to the trajectory positions. A growing BL may cause a downward heat flux from the inversion layer. The sensitivity to this entrainment through the capping temperature inversion was also tested by using a simple approach relating entrainment to the surface heat fluxes, but was found to be negligible relative to other restrictive assumptions.

The initial air temperature is set equal to the ice surface temperature at the trajectory starting point. The impact of this simplified assumption is small when the model is run long enough to reach an equilibrium state. An estimation of the necessary trajectory length can

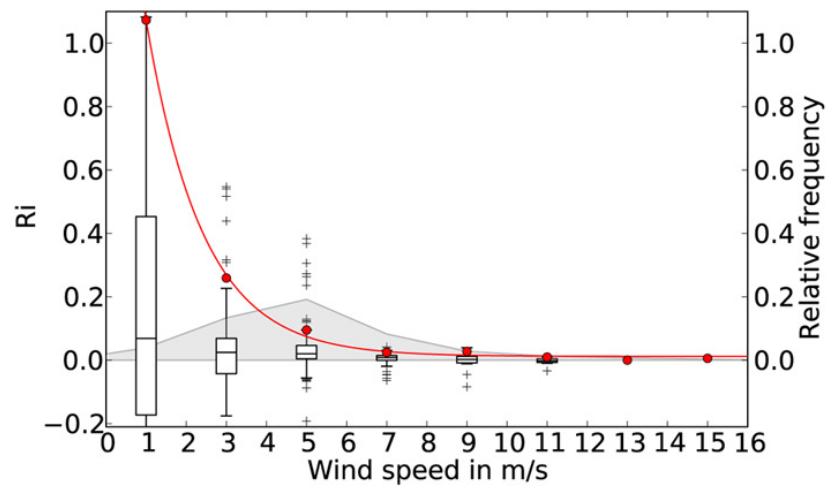

Fig. 2. Boxplot of Richardson numbers in the lowest $30 \mathrm{~m}$ for Barrow derived from radiosonde data in wind speed bins of $2 \mathrm{~m} \mathrm{~s}^{-1}$ (box: quartiles; whiskers: 1.5 times the inner quartile range). The red line is a polynomial fit to the $90 \%$ quantiles, and the gray shaded area is the frequency distribution of wind speed.

be derived from the e-folding time, which can be obtained analytically by using constant transfer coefficients. The solution to Eq. (2) leads to the following:

$t_{\mathrm{e}}=\frac{H}{|\boldsymbol{u}|\left(A \cdot C_{\mathrm{si}}+(1-A) \cdot C_{\mathrm{sw}}\right)}$.

$t_{\mathrm{e}}$ is a function of the boundary layer depth $H$, the wind speed $|\boldsymbol{u}|$ and the ice concentration $A$. To estimate a maximum e-folding time, a wind speed of $5 \mathrm{~m} \mathrm{~s}^{-1}$, an ice concentration of $95 \%$ and a BL depth of $350 \mathrm{~m}$ are assumed. The turbulent transfer coefficients are calculated assuming constant potential temperatures of $-20^{\circ} \mathrm{C}$ for air and $-25^{\circ} \mathrm{C}$ for ice. This gives an e-folding time of $27 \mathrm{~h}$, corresponding to $480 \mathrm{~km}$ length. Therefore, the trajectory length should be larger than $27 \mathrm{~h}$ to ensure that the initial conditions have a small impact. However, in most considered cases, the efolding time is much smaller, and even after $2 \mathrm{~h}$ the modeled temperature only differs by $0.5^{\circ} \mathrm{C}$ from the equilibrium temperature. Nevertheless, the development along trajectories of $30 \mathrm{~h}$ is considered.

\section{Results}

\subsection{Trajectory positions}

The trajectories calculated using the different reanalyses show large inconsistencies. Examples are shown in Fig. 3. The paths of all trajectories are compared by calculating the mean spatial distances between JRA and ERA $\left(1.5^{\circ}\right)$ trajectories, which differ for the three stations. Mean separations after $10 \mathrm{~h}$ are about $50 \mathrm{~km}$ for Barrow, $70 \mathrm{~km}$ for Alert and $90 \mathrm{~km}$ for Tara. The differences between the three stations are even larger after $30 \mathrm{~h}$, ranging from $120 \mathrm{~km}$ for Barrow to $380 \mathrm{~km}$ for Tara. This shows a large inconsistency of the near-surface wind fields of the reanalyses over Arctic sea ice, 


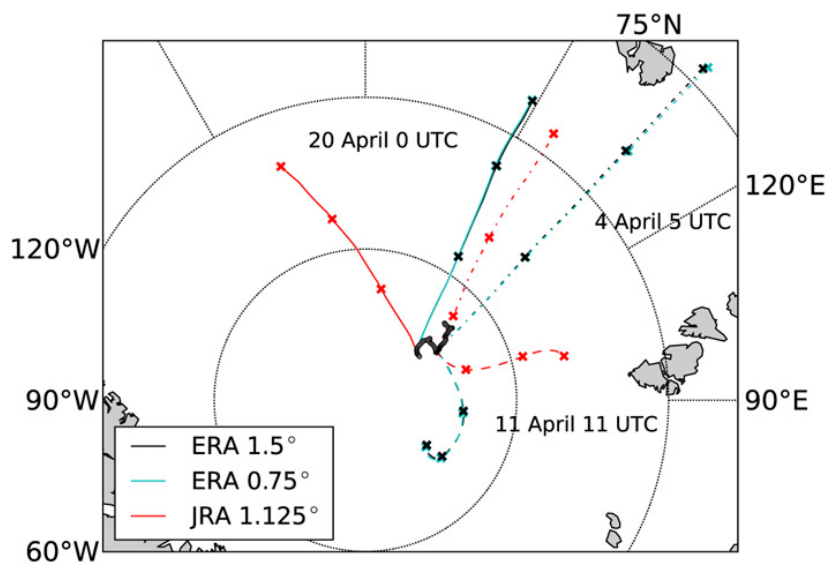

Fig. 3. Three exemplary sets of trajectories arriving at Tara in 2007 calculated using ERA-Interim with two different resolutions and JRA. The temporal differences between crosses are $10 \mathrm{~h}$. The pairs of ERA trajectories are nearly overlapping so that the differences between the trajectories of both ERA data sets are invisible.

especially in the Central Arctic. The large uncertainties in the trajectory positions cause large uncertainties in the estimation of the impact of remote areas, but in the near environment of about $100 \mathrm{~km}$ the uncertainties are on average much smaller.

Comparing ERA-Interim trajectories with resolution of 0.75 and $1.5^{\circ}$ reveals only small mean separations of less than $20 \mathrm{~km}$ after $30 \mathrm{~h}$. Figure 3 also illustrates that using a higher resolution hardly changes the positions of ERA trajectories. Therefore, the lower resolution is used for the following calculations.

\subsection{An example of evolution along a single trajectory}

First, an example is presented showing the development of the air temperature and sensible heat fluxes obtained using the box model along an individual trajectory. It is the trajectory arriving at Tara on 20 April 2007 at 12:00 UTC (Fig. 4), which has AMSR-E ASI ice concentrations between 85 and $99 \%$ along the path. The air parcel moves about $750 \mathrm{~km}$ northward in $30 \mathrm{~h}$. The ice surface temperature varies between -24 and $-14{ }^{\circ} \mathrm{C}$ (Fig. 5). The sensible heat fluxes do not exceed $200 \mathrm{Wm}^{-2}$ over water, because air-sea temperature differences are $17^{\circ} \mathrm{C}$ at maximum and the wind speed does not exceed $7 \mathrm{~m} \mathrm{~s}^{-1}$. The resulting net heat flux is positive in the first $18 \mathrm{~h}$, with small values below $30 \mathrm{Wm}^{-2}$, causing an increase in the potential temperature of $4{ }^{\circ} \mathrm{C}$. At $t=-12 \mathrm{~h}$ a decrease of the ice surface temperature by $10^{\circ} \mathrm{C}$ causes negative net heat fluxes of up to $-50 \mathrm{Wm}^{-2}$ and a decrease in the air temperature of $4^{\circ} \mathrm{C}$ in $5 \mathrm{~h}$. The resulting modeled 2-m temperature at Tara of $-16.8^{\circ} \mathrm{C}$ agrees well with the measured value within $0.1^{\circ} \mathrm{C}$.

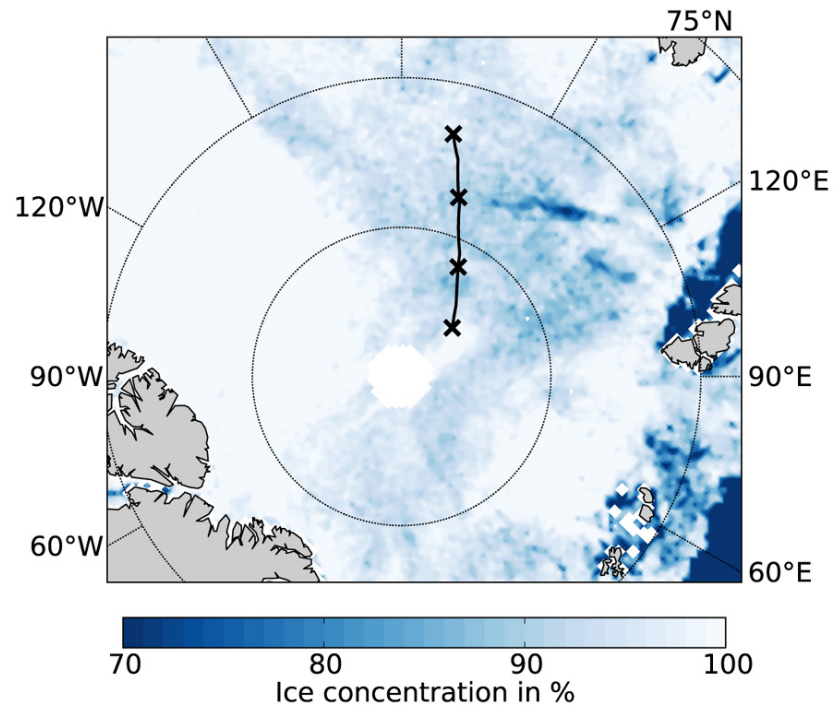

Fig. 4. AA ice concentration on 20 April 2007 and ERA trajectory from 20 April 2007 12:00 UTC during the last $30 \mathrm{~h}$ arriving at Tara (black line).The differences between crosses are $10 \mathrm{~h}$. At this time Tara is located at $87.6^{\circ} \mathrm{N}, 134.9^{\circ} \mathrm{E}$.

The corresponding ERA 2-m temperatures are too high along the trajectory path, with a value of $-12.6^{\circ} \mathrm{C}$ arriving at Tara. This example shows the important role of the specified surface boundary conditions of a model on the calculated air temperature evolution. While the box model, which uses ice concentrations and ice surface temperatures derived from remote sensing data, reproduces the measured 2-m air temperature quite well, the temperature of the reanalysis is about $4{ }^{\circ} \mathrm{C}$ too high. This is probably due to the sea ice boundary conditions in ERA-Interim with fixed values for the ice thickness of $1.5 \mathrm{~m}$ (White, 2006) and for the ice concentration of $100 \%$ north of $82.5^{\circ} \mathrm{N}$ (Inoue et al., 2011), which reduce the surface temperature variability.

\subsection{Ice concentration along all trajectories}

In the following, the geographical locations of the trajectories and the corresponding ice conditions are examined to obtain a basis for further discussions of differences between the stations. Abbreviations for ice concentrations used in this section are according to Table 1 but without the prefix for the reanalysis. The frequency distributions of ice concentrations obtained from remote sensing data for the trajectories resulting from ERA or JRA wind fields are very similar. Therefore, the distributions for both reanalyses are combined in Fig. 6 .

Most trajectories arriving at Alert originate from the Central Arctic north of Greenland (Fig. 1) where high ice concentrations are present due to convergent ice drift. Comparing the distribution of ice concentrations along all trajectories shows that more than $95 \%$ of the time ice concentrations are $98 \%$ or higher for the three AMSR-E data sets (Fig. 6). SSM/I ASI has a heavier tail with about $30 \%$ of the values 

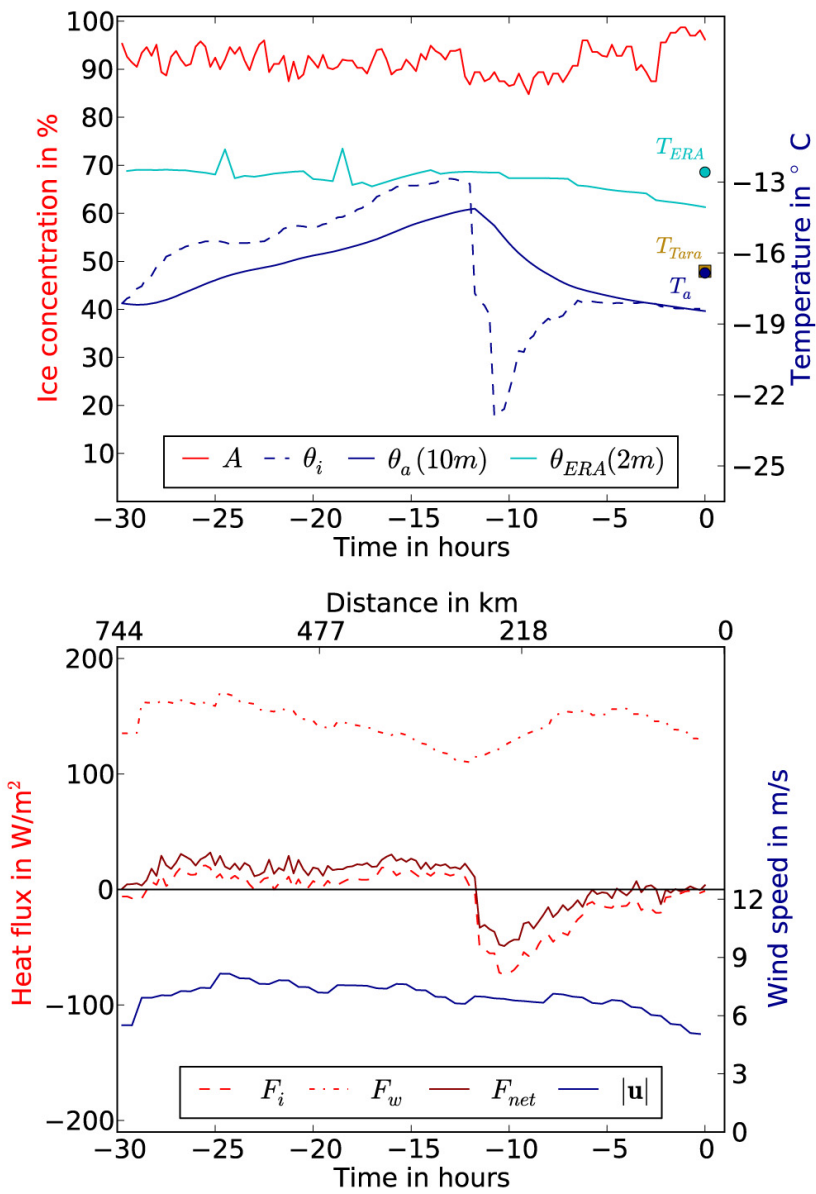

Fig. 5. Time series of the model input and output data on 20 April 2007, 12:00 UTC for Tara, AA ice concentration $(A)$, ice surface potential temperature $\left(\theta_{\mathrm{i}}\right)$, air potential temperature at $10 \mathrm{~m}$ $\left(\theta_{\mathrm{a}}\right)$ (lines) and 2-m air temperature at Tara (symbols) observed and calculated from the predicted $10-\mathrm{m}$ potential temperature, sensible heat flux from ice $\left(F_{\mathrm{i}}\right)$, water $\left(F_{\mathrm{W}}\right)$ and the resulting net flux $\left(F_{\text {net }}\right)$, and ERA surface wind speed $(u)$ and 2-m potential temperature $\left(\theta_{\text {ERA }}\right)$. The BL depth is $350 \mathrm{~m}$. The $2-\mathrm{m}$ air temperature at Tara ( $\left.T_{\text {Tara }}\right)$ is plotted for comparison.

between 90 and $98 \%$. Barrow's trajectories originate from the Beaufort Sea (Fig. 1) where divergences in the Beaufort Gyre decrease the ice concentration. The frequency distribution also reveals lower ice concentrations than for Alert (Fig. 6), with a total of $10 \%$ (AA) up to $50 \%$ (SA) below $98 \%$.

The considered trajectories arriving at Tara originate from the Central Arctic and the Laptev Sea (Fig. 1). Ice concentrations show a larger variability and lower values than for Alert and Barrow. During $75 \%$ of the time, the ice concentration values are below $95 \%$ for SA. The difference between the ice concentration data sets is largest for Tara, with $40 \%$ of the total ice concentrations below $97 \%$ for AA, $25 \%$ below $97 \%$ for $\mathrm{AB}$ and almost $100 \%$ above $97 \%$ for AN. While $\mathrm{AB}$ and $\mathrm{AN}$ show only small changes in the frequency distri-
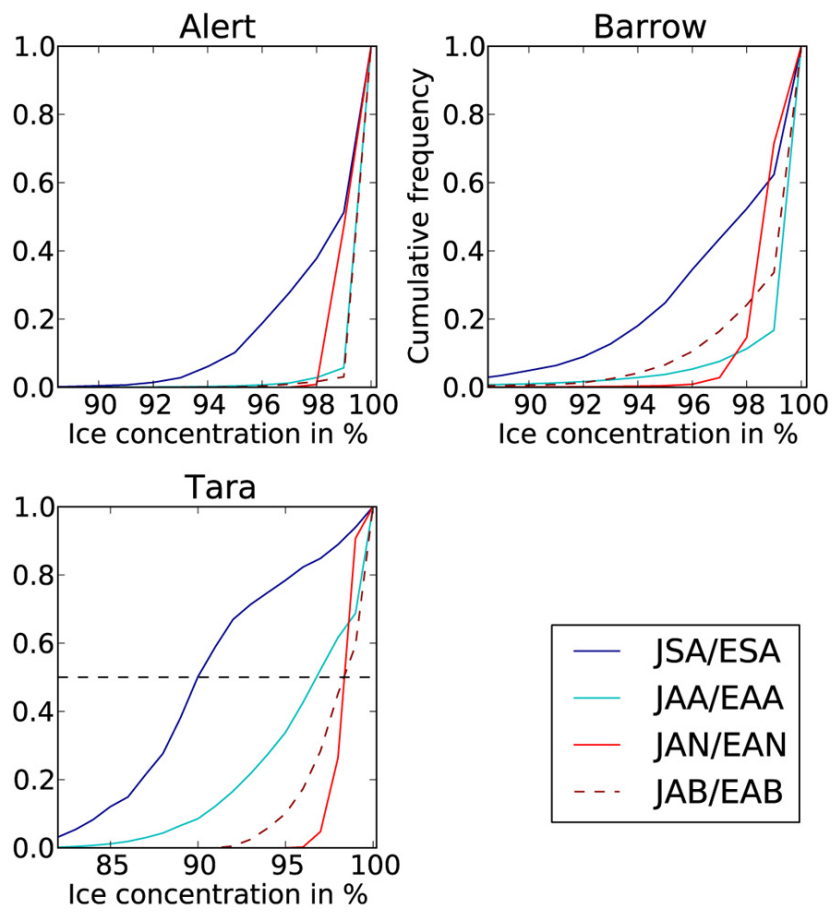

Fig. 6. Cumulative frequency distribution of ice concentrations along the trajectories (ERA and JRA combined) for different ice concentration data sets for Alert, Barrow and Tara.

butions of ice concentration for the three stations, SA and AA show the highest ice concentrations for Alert and the lowest ones for Tara.

\subsection{Results for the ensemble of trajectories}

The correlations between the observed 2-m air temperatures and the mean ice surface temperatures along the trajectories (IST) and modeled temperatures (AT) are positive, exceeding values of 0.6, and significant at the $95 \%$ level for all combinations of reanalyses, ice concentration data sets and BL depths. The results of the AT method obtained with different ice concentrations show differences in the order of 1 to $3 \%$ but overlapping confidence intervals. Since the sensitivity of the results to different ice concentration data sets is very small, only exemplary results (AA) are presented.

Using the AT method, the highest explained variances exceeding $90 \%$ are found for Alert. There, the scatter plot shows a good agreement between model and in situ temperatures for EAA (Fig. 7). For ERA, explained variances are about $6 \%$ higher than for JRA (Fig. 8). The best results are obtained using a BL depth of $100 \mathrm{~m}$, with biases of $-0.6^{\circ} \mathrm{C}$ (ERA) and $-1.4^{\circ} \mathrm{C}$ (JRA) and RMSE of $2.1^{\circ} \mathrm{C}$ (ERA) and $3.1^{\circ} \mathrm{C}$ (JRA). Using ERA BL depths gives similar results, while using $350 \mathrm{~m}$ increases the negative biases to $-1.8^{\circ} \mathrm{C}$ (ERA) and $-2.2^{\circ} \mathrm{C}$ (JRA). The explained variance based on the IST method is $89 \%$ using ERA and $86 \%$ using JRA, which is the same order as the model results. Biases and 


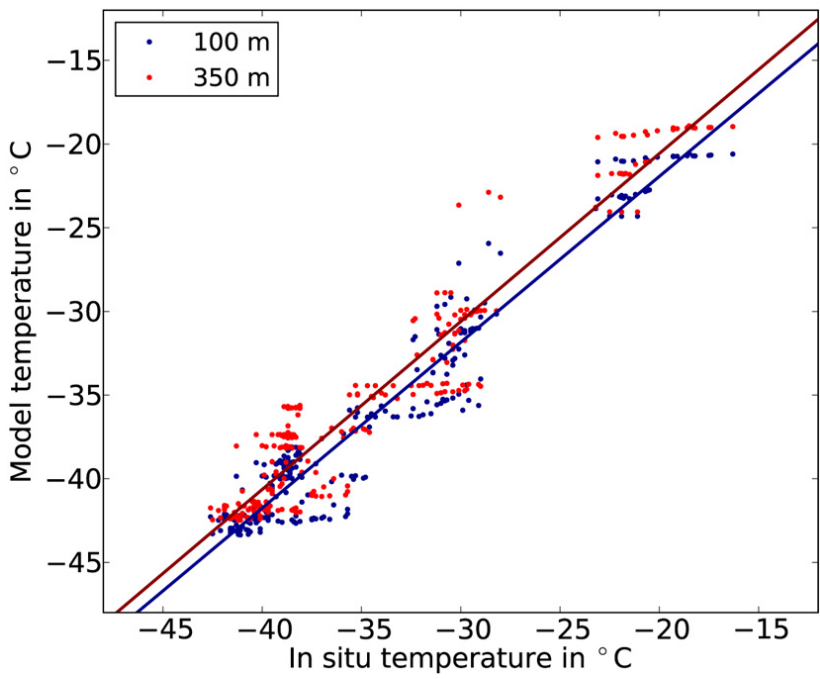

Fig. 7. Scatter plot of in situ and modeled temperatures (AT method) in ${ }^{\circ} \mathrm{C}$ for Alert 2003-2006 for EAA. The colors denote the BL depths and the lines are the corresponding regression lines.

RMSE using the IST method are larger than those from the AT method.

Explained variances for Barrow are smaller than for Alert, ranging between 61 and $74 \%$ for the AT method and between 46 and $51 \%$ using the IST method (Fig. 8). In all cases, values for a BL depth of $350 \mathrm{~m}$ are up to $10 \%$ higher than for $100 \mathrm{~m}$ and about $5 \%$ higher than for the run with ERA BL depths. Temperature biases are positive in the order of 1.5 $(350 \mathrm{~m})$ to $3.5^{\circ} \mathrm{C}(100 \mathrm{~m})$ and the RMSE range from 3 to $4^{\circ} \mathrm{C}$. Biases from the IST method are negative with values around $-0.8^{\circ} \mathrm{C}$.

Tara shows the largest sensitivity to different reanalyses for the AT method. Explained variances are about $70 \%$ using JRA trajectories with RMSE of about $3.6^{\circ} \mathrm{C}$ (Fig. 8). Using ERA trajectories gives larger explained variances in the order of $80 \%$ with RMSE of $3.3^{\circ} \mathrm{C}(100 \mathrm{~m})$ to $3.9^{\circ} \mathrm{C}(350 \mathrm{~m})$. For both reanalyses higher explained variances are obtained using a BL depth of $100 \mathrm{~m}$. The variance from the IST method is about $20 \%$ smaller than the explained variance from the AT method. The RMSE are of the same order and the bias based on the IST method of $-1.7^{\circ} \mathrm{C}$ is even smaller than the biases based on the AT method of about $-2.5^{\circ} \mathrm{C}$.

In addition, ERA BL depths are compared with the two constant values. For Barrow, most ERA derived BL depths can be found around $150 \mathrm{~m}$ (Fig. 9), but the distribution has a tail with some BL depths even exceeding $500 \mathrm{~m}$. This explains why results of the AT method are better for BL depths of $350 \mathrm{~m}$ than for $100 \mathrm{~m}$. In Alert, BL depths below $100 \mathrm{~m}$ are present in the ERA data and the biases and RMSE are also lower for a BL depth of $100 \mathrm{~m}$. These results are in line with the expected results from the ice concentration distributions. Shallow BLs develop over completely ice covered areas, as observed for Alert, whereas more open water areas,
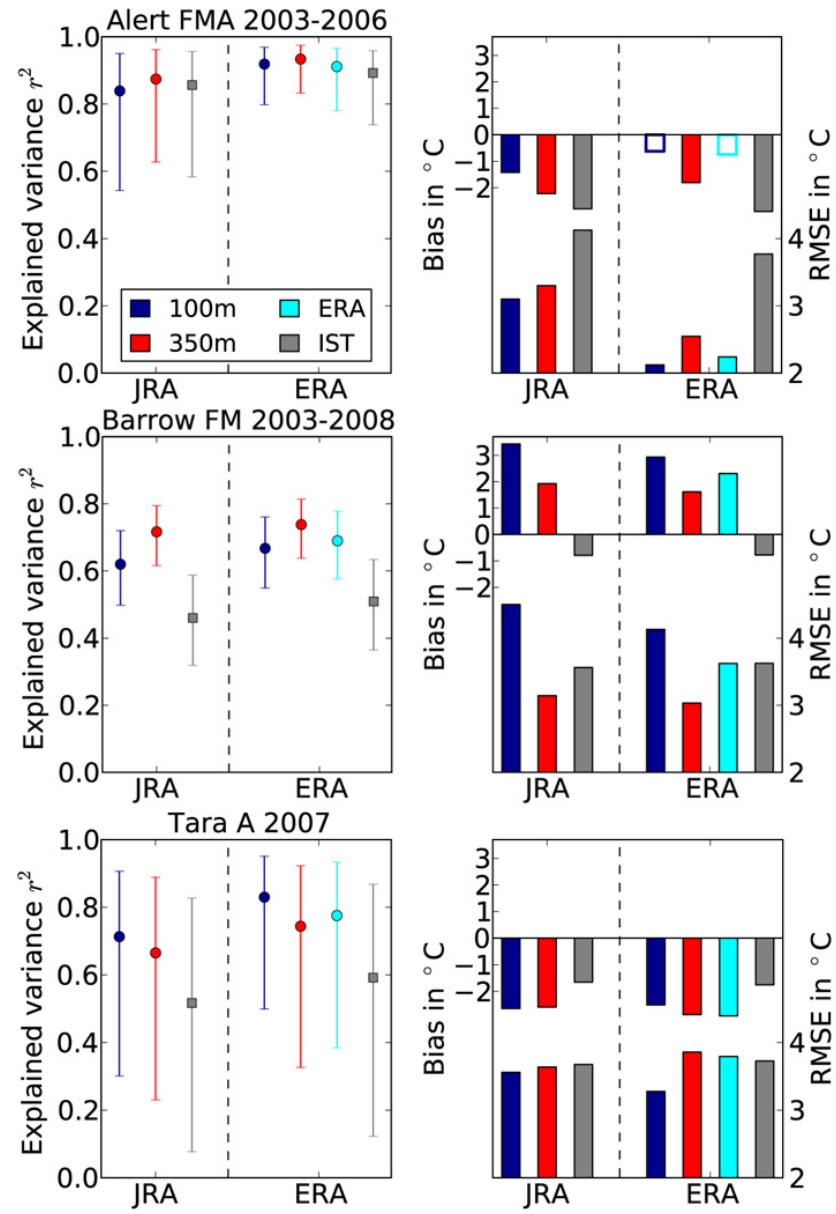

Fig. 8. Explained variances between observed 2-m air temperatures at the stations and modeled temperatures (AT method, colored), as well as mean ice surface temperatures along the trajectories (gray) with $95 \%$ confidence intervals (left), bias and RMSE (right) for Alert (upper), Barrow (middle) and Tara (lower), using AA ice concentrations. The colors denote the BL depths. The blank bars are not significant at the $95 \%$ level.

as for Barrow, cause a deepening of the BL. The BL depths are the largest at Tara. Here, the most frequent values range from 100 to $400 \mathrm{~m}$. However, explained variances using the AT method are larger for a BL of $100 \mathrm{~m}$ than for a BL of $350 \mathrm{~m}$ for both reanalyses.

\subsection{Radius of impact}

The above analysis does not yet answer the question concerning the dominant horizontal scale $R$ (or the corresponding time scale $R_{t}$ ) influencing the $2-\mathrm{m}$ air temperature. Therefore, in addition to the previous studies, results are considered as a function of the trajectory length, which is reduced stepwise from 30 to $2 \mathrm{~h}$. Figure 10 shows results obtained using the AT and the IST methods corresponding to the prescribed trajectory length. Results are exemplarily discussed for JAA; results from ERA differ only slightly. 


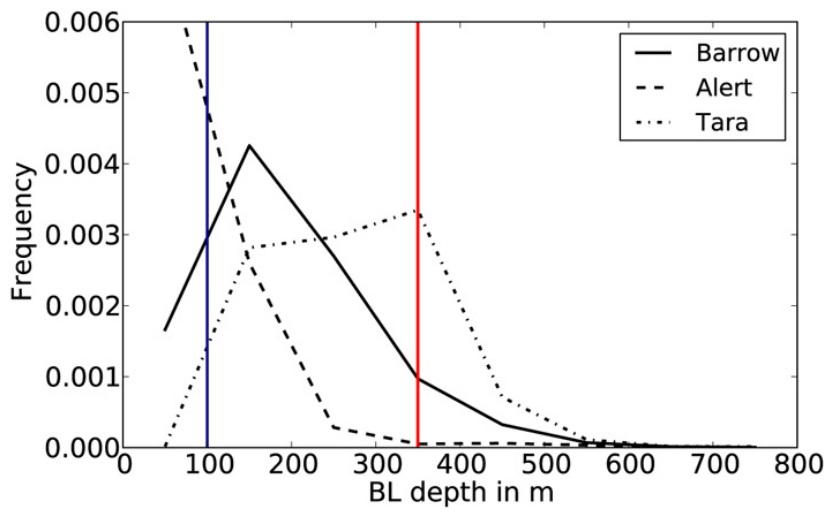

Fig. 9. Frequency distribution of ERA-Interim BL depths for Barrow, Alert and Tara. The two constant BL depths that are also used are marked with colors.

The clearest results are those for Barrow. There, the explained variances obtained using the AT method increase by about $6 \%$ with increasing trajectory length from 2 to $10 \mathrm{~h}$, while they remain nearly constant from 10 to $30 \mathrm{~h}$. The corresponding curve based on IST shows a different behavior with a maximum of explained variance for $5 \mathrm{~h}$. For the IST method the explained variance decreases for distances larger than $R$ or for times larger than $R_{t}$, because the surface temperatures in remote areas are no longer correlated with the considered location. A similar decrease for the explained variance of the AT method is not seen, because all trajectories starting at time $t>R_{t}$ pass also the region close to the location with large impact.

For Barrow, biases and RMSE decrease by about $1{ }^{\circ} \mathrm{C}$ for trajectory lengths between 2 and $10 \mathrm{~h}$ and remain nearly constant for larger lengths using the AT method. The minimum RMSE using the IST method is found for trajectory lengths of about 10 to $20 \mathrm{~h}$. The bias from IST increases for shorter trajectory lengths from -1 to $4^{\circ} \mathrm{C}$. Both methods suggest a value $R_{t}=10 \mathrm{~h}$ for the characteristic time scale, corresponding to $R \approx 180 \mathrm{~km}$ for an average wind speed of $5 \mathrm{~m} \mathrm{~s}^{-1}$.

For Alert, the results using the AT method improve only slightly for longer trajectories. Distinct changes can be found in the curves for bias and RMSE of the IST method, suggesting $R_{t}=10 \mathrm{~h}$, as found for Barrow. Results for Tara with respect to $R$ values are ambiguous. The curves for bias and RMSE using the IST method indicate a radius of impact of about $5 \mathrm{~h}$, while the results using the AT method hardly change with decreasing trajectory length. However, only one month of data is used for Tara, which might not be long enough to draw reliable conclusions concerning the comparison of results for Tara and both other stations.

These results are supplemented by explained variances calculated using the TV method (Fig. 11). For Alert and Barrow, the explained variances increase monotonically with increasing trajectory length, which shows that heat fluxes in remote areas can have a certain impact on the air temperature at
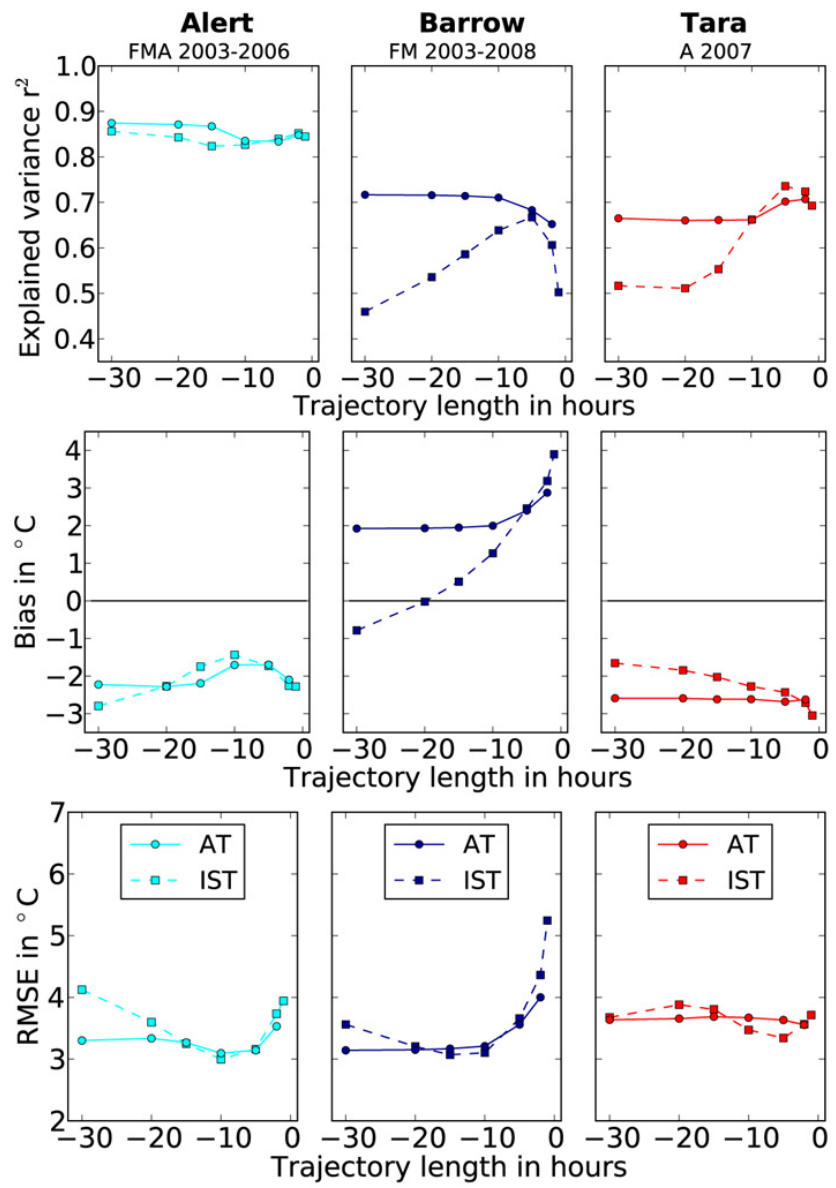

Fig. 10. Explained variances (upper), bias (middle) and RMSE (lower) for Alert, Barrow and Tara (JAA) as a function of trajectory length using the IST and AT methods, with $350 \mathrm{~m} \mathrm{BL}$ depth in the latter.

a given location. However, the largest impact in this method is also seen in the first $10 \mathrm{~h}$, where the slope of the curves is the largest. Therefore, a radius of main impact can be defined by relating it to the region with the largest slope of the curves. By this definition, $R_{t}$ is reached at the transition from steeper to shallower slopes. This transition is pronounced for all stations at a trajectory length of $10 \mathrm{~h}$, which is consistent with the results from the AT method.

Correlation length scales for surface air temperatures have also been calculated by Rigor et al. (2000). They correlated 12-hourly temperature data measured at land and ocean stations in the Arctic during 1979 to 1997. In winter, correlations decreased to about 0.8 (corresponding to an explained variance of 0.64 ) for separations between the stations of 300 to $400 \mathrm{~km}$ (their Fig. 5). Thus, despite the different methods used, the results are of the same order of magnitude as the radius of impact found in the present study. 


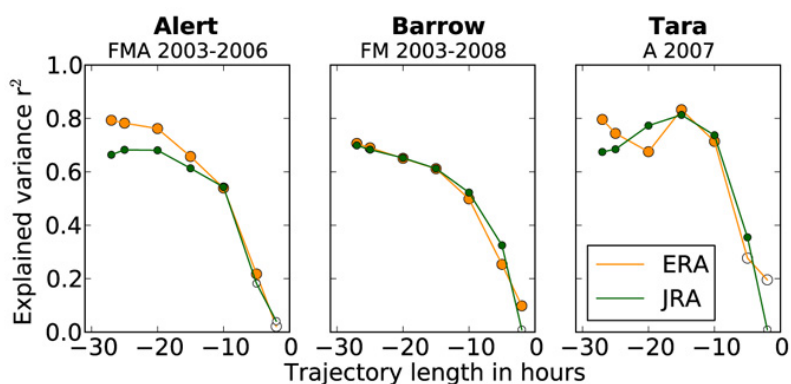

Fig. 11. Explained variances of temperature difference between the model starting temperature and the observed 2-m air temperature at the station and mean sensible heat flux along the trajectories (TV method) for Alert, Barrow and Tara (AA) as a function of trajectory length using a BL depth of $350 \mathrm{~m}$. The filled circles are significant at the $95 \%$ level.

\section{Discussion}

One can see that the different methods having been applied explain the observed variances in general quite well. However, the RMSE values are as large as 3 to $4^{\circ} \mathrm{C}$. Possible reasons for these large differences of modeled and in situ temperatures are discussed in the following.

\subsection{Uncertainties of input data}

Comparing trajectory positions calculated from the surface wind fields of the two reanalyses reveals large differences in the order of $100 \mathrm{~km}$ after $15 \mathrm{~h}$. This points to large uncertainties in the surface wind fields. Jakobson et al. (2012) compared wind speed profiles from tether-sonde sounding data at Tara to different reanalyses. Using 29 profiles, they found that the ERA and JRA reanalyses generally agree well but slightly overestimate the $10-\mathrm{m}$ wind speeds by about $1 \mathrm{~m} \mathrm{~s}^{-1}$ with an RMSE of only $1.5 \mathrm{~m} \mathrm{~s}^{-1}$. Uncertainties of $1 \mathrm{~m} \mathrm{~s}^{-1}$ can cause separations of trajectories in the order of $100 \mathrm{~km}$ after $30 \mathrm{~h}$ and will influence the flux calculations. Increasing the wind speed by $1 \mathrm{~m} \mathrm{~s}^{-1}$ in a sensitivity study (not shown) caused changes of the model temperature by up to $1^{\circ} \mathrm{C}$ for individual trajectories. However, the mean impact on the correlation and RMSE for the ensemble of trajectories was found to be small.

There are also uncertainties in the location of the trajectory points arising from the calculation method. In reality, air motions are not only horizontal - air parcels also experience rising and sinking. Since wind speed and direction usually change with height, neglecting vertical motions leads to errors in the positions. Thus the representation of an air parcel as a box extending over the entire BL with constant wind represents in most cases only a rough approximation of natural conditions.

Ice concentrations are available only on a daily basis with a grid spacing of $12.5 \mathrm{~km}$ (and $6.25 \mathrm{~km}$ for AA). This means that small-scale features and ice concentration changes on shorter timescales are not captured. Furthermore, there are also uncertainties in the retrieval method. Andersen et al. (2007) compared ice concentrations from SSM/I data using different algorithms to SAR data in winter. They found that the ASI algorithm tends to underestimate ice concentrations close to $100 \%$ by $2.1 \%$ and that ice concentrations have an uncertainty range of $3.9 \%$. NT2 shows a smaller underestimation of $0.4 \%$, similar to Bootstrap with $0.3 \%$, with a larger uncertainty range of $4.9 \%$ in regions with high ice concentrations. A comparison of the algorithms for AMSR-E data in the Arctic show that overall ASI ice concentrations are $1.4 \%$ smaller than Bootstrap and $2.0 \%$ smaller than NT2 ice concentrations (Spreen et al., 2008). Furthermore, Shokr and Kaleschke (2012) showed that ice concentrations are underestimated in the presence of thin ice below $12 \mathrm{~cm}$ thickness, depending on the surface conditions. The impact of a constant error in the ice concentration of $5 \%$ was investigated in sensitivity studies (not shown) and found to be small, causing model temperature changes of less than $0.5^{\circ} \mathrm{C}$. Since ice concentration data along the trajectories are above $90 \%$ in most cases (Fig. 6), the effect of an underestimated ice concentration by a few percent in the presence of thin ice can be expected to be small.

There are also uncertainties concerning the ice surface temperatures. Hall et al. (2004) compared MODIS ice surface temperatures to in situ measurements and found uncertainties in the order of $1.3^{\circ} \mathrm{C}$. In addition, the considered cases may still contain clouds, which notably influence the ice surface temperature (Vihma and Pirazzini, 2005). There are uncertainties concerning the cloud mask, and fog is sometimes not classified as clouds (Hall et al., 2006). Furthermore, even if there were no clouds present during the overpass of the satellite, there might still be cloudy conditions at the time of the trajectory path. An attempt to use cloud data from the reanalyses turned out to be impracticable due to the larger grid sizes. Additional uncertainties arise because of the inaccurate trajectory positions. A displacement of $20 \mathrm{~km}$ can cause uncertainties in the MOD29 ice surface temperatures of up to $2{ }^{\circ} \mathrm{C}$ (not shown). The impact of these large uncertainties is investigated by assuming a constant offset between MOD29 and real ice surface temperatures of $1^{\circ} \mathrm{C}$. The average changes in the modeled temperature were in the order of $1{ }^{\circ} \mathrm{C}$, resulting in changes of the bias and RMSE of up to $1^{\circ} \mathrm{C}$ (not shown). This means that the largest source of uncertainties in the methods used is due to inaccurate ice surface temperatures, which are mainly caused by inaccurate trajectory positions and by radiative effects from undetected clouds.

Despite these uncertainties the analyses show that spatial surface temperature variability in the surrounding of a location has a significant impact on 2-m air temperatures at this location. This shows that a good representation of ice concentration and ice thickness in models would improve not only temperatures but also surface winds, since ice concentrations also influence the shape of the wind profile (Tisler et al., 2008) and even the atmospheric pressure patterns. 


\subsection{Impact of model assumptions}

Several model assumptions and simplifications mentioned already in Sect. 3 should also be kept in mind for the interpretation of results obtained by the AT and the TV method. Additional uncertainties that might be responsible for the large RMSE arise, for example, from the roughness lengths used for momentum $z_{0}$ and heat $z_{T}$, which are set constant in the model using the relation $z_{T} / z_{0}=10^{-1}$ for simplicity. For this reason, different constant values of $z_{0}$ and $z_{T}$ over sea ice have been tested, but the impact was moderate on both RMSE and biases and the explained variance changed only little. However, it cannot be excluded that variable values accounting for the sea ice topography (Andreas et al., 1984; Garbrecht et al., 1999, 2002; Vihma et al., 2003; Guest and Davidson, 1987; Lüpkes and Birnbaum, 2005; Stössel and Claussen, 1993) would have a larger impact. This cannot be tested here, because the sea ice topography is dominated by pressure ridges in regions with large sea ice concentration and topography data are not available. Estimating the variability of drag coefficients by parameterizations accounting for sea ice concentration (Andreas et al., 2010; Lüpkes et al., 2012a) shows that its impact on drag coefficients is only small in our case. This would be different during summer or in the marginal sea ice zones where the surface topography is determined by ice floe edges and edges at melt ponds, so that it can be parameterized as a function of sea ice concentration as described in the above-mentioned literature.

It should also be stressed that the present method does not allow the modeling of the feedback mechanism of the atmospheric processes on sea ice, since ice concentrations and ice surface temperatures are prescribed from satellite data. This implies that, although only sensible heat fluxes occur as a direct source for temperature change in the model equation, other processes that have contributed to the observed surface temperature variability are also indirectly accounted for. Such processes are, for example, heat transport through ice and radiation. A variation of parameters like surface roughness would also affect the surface temperature and sea ice drift, but this kind of interaction is excluded by prescribing the observed surface temperature. This means that the model underestimates the impact of sea ice variability, which can only be obtained by a fully coupled ice atmosphere model.

In addition, the ice concentration only represents the mean ice conditions in one pixel of $12.5 \mathrm{~km}$ (or $6.25 \mathrm{~km}$ for AA). It does not contain any information about the spatial distribution of open water areas in the pixel area. Andreas and Cash (1999) have shown that the heat transfer from wintertime leads and polynyas is more efficient for small leads. They found transfer coefficients of $1.0 \times 10^{-3}$ for a fetch larger than $100 \mathrm{~m}$ and of $1.8 \times 10^{-3}$ for smaller fetches. Maslanik and Key (1995) calculated that a fetch increase from 10 to $100 \mathrm{~m}$ decreases sensible heat fluxes from an open water lead by $34 \%$. This means that the spatial distribution, size and orientation of open water areas influence the heat transfer and that our present estimation of open water impact can be seen as a lower limit, and the real impact could be much larger (Marcq and Weiss, 2012).

\section{Conclusions}

The main goal of this study was to investigate the dependence of the 2-m air temperature on the surface temperature variability around three Arctic sites and to determine its characteristic radius of impact. These sites were Alert, Barrow and the French schooner Tara during its drift across the Arctic ocean. Three approaches were used, based on backward trajectories calculated from $10-\mathrm{m}$ wind fields of the ERAInterim and the JRA25 reanalyses. As a first step, the 2-m air temperature measured at the stations was correlated with the average MODIS sea ice surface temperature along the trajectory paths. For the other two methods, a simple Lagrangian box model, which was run along the trajectories, was applied to calculate the surface sensible heat fluxes and the air temperature evolution along the trajectories. Four different ice concentration data sets (SSM/I ASI, AMSR-E ASI, NASA Team 2 and Bootstrap) and MODIS ice surface temperatures were used. For the AT method the modeled temperatures at the stations were compared to the measured ones, and for the TV method temperature changes between the model temperature at the trajectory starting point and in situ measurements at the stations were compared to mean sensible heat fluxes. The investigation was carried out for the cold season with only few clouds, to restrict the study to conditions where a large impact of surface fluxes can be expected.

It is found that the AT method explains a large amount, namely 70 (Barrow) to $90 \%$ (Alert), of the observed 2-m air temperature variability at all stations. All methods give slightly better results using ERA trajectories than using those derived from the JRA reanalysis. The results depend only weakly on the sea ice concentration products, although they show significant differences in the sea ice distributions. For example, the correlation coefficient between measured and calculated 2-m temperatures at the different sites changes only by $10^{-4}$ for a $5 \%$ change of sea ice concentration. This small sensitivity can be explained by the independence of measured ice surface temperatures and ice concentrations. However, in an atmospheric model coupled with a thermodynamic sea ice model, such as ERA-Interim, the ice surface temperature adjusts to the ice concentration and ice thickness, and thus changes of the ice concentration would have a larger effect (Lüpkes et al., 2008).

In most considered cases, the IST method explains a smaller percentage of the 2-m air temperature than the AT method (though values still range between 46 and $89 \%$ for Barrow and Alert, respectively). This points to the fact that the spatial variability of the far field contributes noticeably to a local temperature that is otherwise dominated by the near field surface conditions. 
The results show the highest sensitivity to uncertainties in the ice surface temperatures. These are mainly due to uncertainties in the trajectory positions and radiative effects from undetected clouds. The characteristic radius of impact of sea ice concentration and surface temperature variability was investigated by varying the trajectory lengths and was found to be in the order of $200 \mathrm{~km}$, assuming an average wind speed of $5 \mathrm{~m} \mathrm{~s}^{-1}$. This radius is robust for Barrow and Alert using all three methods.

In general, all results for Tara are less relevant compared with those for Alert and Barrow, since only one month of data is used for the calculations. But at least the TV method also indicates a radius of impact in the order of $200 \mathrm{~km}$ which does not contradict the findings for the other two stations.

The present results should be viewed in light of restrictive model assumptions and uncertainties of input data. Nevertheless, they reveal a large dependence of atmospheric boundary layer temperatures on heterogeneous surface temperatures in the Arctic, underlining the large importance of a very accurate representation of all processes that influence the surface temperature in climate and weather prediction models.

\section{Appendix A}

\section{Integration of the model equation}

The solution to the model equation (Eq. 1) depends on the assumptions concerning the vertical potential temperature profile in the boundary layer. For example, the temperature profile above the reference height of $z_{\text {ref }}=10 \mathrm{~m}$ can be expressed as a power law:

$\theta(z)=\left(\theta(H)-\theta\left(z_{\mathrm{ref}}\right)\right)\left(\frac{z-z_{\mathrm{ref}}}{H-z_{\mathrm{ref}}}\right)^{b}+\theta\left(z_{\mathrm{ref}}\right)$.

This relationship includes a linear temperature profile for an exponent $b=1$ and a well-mixed BL for $b=0$. With the assumption of a constant BL thickness $H$, the time derivative of Eq. (A1) is

$$
\frac{\mathrm{d} \theta(z)}{\mathrm{d} t}=\frac{\mathrm{d}\left(\theta(H)-\theta\left(z_{\mathrm{ref}}\right)\right)}{\mathrm{d} t}\left(\frac{z-z_{\mathrm{ref}}}{H-z_{\mathrm{ref}}}\right)^{b}+\frac{\mathrm{d} \theta\left(z_{\mathrm{ref}}\right)}{\mathrm{d} t}
$$

When the temperature difference $\left(\theta(H)-\theta\left(z_{\text {ref }}\right)\right)$ is assumed to be constant in time, the first term on the right-hand side of the equation vanishes, so that $\theta$ and $\theta_{\mathrm{a}}$ can be replaced by $\theta\left(z_{\text {ref }}\right)$ in Eqs. (1) and (2). With these assumptions the solution to Eq. (1) or (2) are always the same for any profile of the form of Eq. (A1). However, we use the well-mixed case in Sect. 3.3 since for $b=0$ the assumption $H=$ const. is not necessary.
Acknowledgements. This study was supported through the Cluster of Excellence "CliSAP" (EXC177), University of Hamburg, funded by the German Science Foundation (DFG). A part of this project was also funded by a subproject of MiKlip, a project supported by the German Federal Ministry of Education and Research (FKZ:01LP1126A). The Tara expedition was supported by the European Commission 6th Framework Integrated Project DAMOCLES and in part by the Academy of Finland through the CACSI project; and we thank Timo Palo, Erko Jakobson and Jaak Jaagus for providing us with the data. ECMWF ERA-Interim data used in this study were obtained from the ECMWF data server. JRA reanalysis data used for this study were provided from the cooperative research project of the JRA-25 long-term reanalysis by the Japan Meteorological Agency (JMA) and the Central Research Institute of Electric Power Industry (CRIEPI). We also appreciate the constructive criticism by Jun Inoue and two anonymous referees that helped improve the manuscript.

Edited by: T. Garrett

\section{References}

Andersen, S., Tonboe, R., Kaleschke, L., Heygster, G., and Pedersen, L. T.: Intercomparison of passive microwave sea ice concentration retrievals over the high concentration Arctic sea ice, J. Geophys. Res., 112, C08004, doi:10.1029/2006JC003543, 2007.

Andreas, E. L. and Cash, B. A.: Convective heat transfer over wintertime leads and polynyas, J. Geophys. Res., 104, 25721-25734, doi:10.1029/1999JC900241, 1999.

Andreas, E. L., Tucker III, W., and Ackley, S. F.: Atmospheric boundary-layer modification, drag coefficient, and surface heat flux in the Antarctic marginal ice zone,, J. Geophys. Res., 89, 649-661, doi:10.1029/JC089iC01p00649, 1984.

Andreas, E. L., Persson, P. O. G., Jordan, R. E., Horst, T. W., Guest, P. S., Grachev, A. A., and Fairall, C. W.: Parameterizing Turbulent Exchange over Sea Ice in Winter, J. Hydromet., 11, 87-104, doi:10.1175/2009JHM1102.1, 2010.

Boisvert, L. N., Markus, T., Parkinson, C. L., and Vihma, T.: Moisture fluxes derived from EOS aqua satellite data for the north water polynya over 2003-2009, J. Geophys. Res., 117, D06119, doi:10.1029/2011JD016949, 2012.

Cavalieri, D., Markus, T., and Comiso, J.: AMSR-E/Aqua Daily L3 $12.5 \mathrm{~km}$ Brightness Temperature, Sea Ice Conentration and Snow Depth Polar Grids V002, National Snow and Ice Data Center,Boulder, Colorado, USA, 2004.

Dee, D. P., Uppala, S. M., Simmons, A. J., Berrisford, P., Poli, P., Kobayashi, S., Andrae, U., Balmaseda, A., Balsamo, G., Bauer, P., Bechtold, P., Beljaars, A. C. M., van de Berg, L., Bidlot, J., Bormann, N., Delsol, C., Dragani, R., Fuentes, M., Geer, A. J., Haimberger, L., Healy, S. B., Hersbach, H., Holm, E. V., Isaksen, L., Kallberg, P., Köhler, M., Matricardi, M., McNally, A. P., Monge-Sanz, B. M., Morcrette, J., Park, B., Peubey, C., de Rosnay, P., Tavolate, C., Thepaut, J., and Vitart, F.: The ERAInterim reanalysis: configuration and performance of the dataassimilation system., Q. J. R. Meteorol. Soc., 137, 553-597, doi:10.1002/qj.828, 2011.

Fiedler, E. K., Lachlan-Cope, T. A., Renfrew, I. A., and King, J. C.: Convective heat transfer over thin ice covered coastal polynyas, J. Geophys. Res., 115, C10051, doi:10.1029/2009JC005797, 2010. 
Garbrecht, T., Lüpkes, C., Augstein, E., and Wamse, C.: Influence of a sea ice ridge on low-level airflow, J. Geophys. Res., 104, 24499-24507, doi:10.1029/1999JD900488, 1999.

Garbrecht, T., Lüpkes, C., Hartmann, J., and Wolff, M.: Atmospheric drag coefficients over sea ice - validation of a parametrisation concept, Tellus A, 54, 205-21, doi:10.1034/j.16000870.2002.01253.x, 2002.

Grachev, A. A., Andreas, E. L., Fairall, C. W., Guest, P. S., and Persson, P. O. G.: SHEBA flux-profile relationships in the stable atmospheric boundary layer, Bound. Layer Met., 124, 315-333, doi:10.1007/s10546-007-9177-6, 2007.

Guest, P. S. and Davidson, K. L.: The effect of observed ice conditions on the drag coefficient in the summer east greenland sea marginal ice zone, J. Geophys. Res., 92, 6943-6954, doi:10.1029/JC092iC07p06943, 1987.

Hall, D. K., Key, J. R., Casey, K. A., Riggs, G. A., and Cavalieri, D. J.: Sea Ice Surface Temperature Product From MODIS, IEEE Trans. Geosc. Rem. Sens., 42, 1076-1087, doi:10.1109/TGRS.2004.825587, 2004.

Hall, D. K., Riggs, G. A., and Salomonson, V. V.: MODIS/Terra Sea Ice Extent and IST Daily L3 Global 4 km EASE-Grid Day V005, National Snow and Ice Data Center, Boulder, Colorado, USA, 2006.

Hartmann, J., Kottmeier, C., and Raasch, R.: Boundary layer development and roll vortex structure during a cold air outbreak, Bound. Layer Met., 84, 45-65, doi:10.1023/A:1000392931768, 1997.

Inoue, J., Curry, J. A., and Maslanik, J. A.: Application of Aerosondes to melt-pond observations over Arctic Sea ice, J. Atmos. Ocean. Tech., 25, 327-334, doi:10.1175/2007JTECHA955.1, 2008.

Inoue, J., Masatake, E. H., Enomoto, T., and Kikuchi, T.: Intercomparison of Surface Heat Transfer Near the Arctic Marginal Ice Zone for Multiple Reanalyses: A Case Study of September 2009, SOLA, 7, 57-60, doi:10.2151/sola.2011-015, 2011.

Jakobson, E., Vihma, T., Palo, T., Jakobson, L., Keernik, H., and Jaagus, J.: Validation of atmospheric reanalyses over the Central Arctic Ocean, Geophy. Res. Lett., 39, L10802, doi:10.1029/2012GL051591, 2012.

Kaleschke, L., Heygster, G., Lüpkes, C., Bochert, A., Hartmann, J., Haarpaintner, J., and Vihma, T.: SSM/I sea ice remote sensing for mesoscale ocean-atmosphere interaction analysis, Can. J. Rem. Sens., 27, 526-537, 2001.

Lüpkes, C. and Birnbaum, G.: Surface drag in the Arctic marginal sea-ice zone: a comparison of different parameterisation concepts, Bound. Layer Met., 117, 179-211, doi:10.1007/s10546005-1445-8, 2005.

Lüpkes, C., Vihma, T., Birnbaum, G., and Wacker, U.: Influence of leads in sea ice on the temperature of the atmospheric boundary layer during polar night, Geophys. Res. Lett., 35, L03805, doi:10.1029/2007GL032461, 2008.

Lüpkes, C., Vihma, T., Jakobson, E., König-Langlo, G., and Tetzlaff, A.: Meteorological observations from ship cruises during summer to the Central Arctic: A comparison with reanalysis data, Geophys. Res. Lett., 27, L09810, doi:10.1029/2010GL042724, 2010.

Lüpkes, C., Gryanik, V. M., Hartmann, J., and Andreas, E. L.: A parametrization, based on sea ice morphology, of the neutral atmospheric drag coefficients for weather predic- tion and climate models, J. Geophys. Res., 117, D13112, doi:10.1029/2012JD017630, 2012a.

Lüpkes, C., Vihma, T., Birnbaum, G., Dierer, S., Garbrecht, T., Gryanik, V., Gryschka, M., Hartmann, J., Heinemann, G., Kaleschke, L., Raasch, S.and Savijärvi, H., Schlünzen, K., and Wacker, U.: ARCTIC Climate Change - The ACSYS Decade and Beyond, vol. 43 of Atmospheric and Oceanographic Sciences Library, chap. 7, Mesoscale modelling of the Arctic atmospheric boundary layer and its interaction with sea ice, Springer, 2012b.

Marcq, S. and Weiss, J.: Influence of sea ice lead-width distribution on turbulent heat transfer between the ocean and the atmosphere, The Cryosphere, 6, 143-156, doi:10.5194/tc-6-143-2012, 2012.

Martin, S., Drucker, R., Kwok, R., and Holt, B.: Estimation of the thin ice thickness and heat flux for the Chukchi Sea Alaskan coast polynya from Special Sensor Microwave/Imager data, 1990-2001, J. Geophys. Res., 109, C10012, doi:10.1029/2004JC002428, 2004.

Maslanik, J. A. and Key, J.: On treatments of fetch and stability sensitivity in large-area estimates of sensible heat flux over sea ice, J. Geophys. Res., 100, 4573-4584, doi:10.1029/94JC02204, 1995.

Meier, W. M., Maslanik, J. A., Key, J. R., and Fowler, C. W.: Multiparameter AVHRR-Derived Products for Arctic Climate Studies, Earth Int., 1, 1-29, doi:10.1175/10873562(1997)001;0001:MADPFA;2.3.CO;2, 1997.

Onogi, K., Tsutsui, J., Koide, H., Sakamoto, M., Kobayashi, S., Hatsushika, H., Matsumoto, T., Yamazaki, N., Kamahori, H., Takahashi, K., Kadokura, S., Wada, K., Kato, K., Oyama, R., Ose, T., Mannoji, N., and Taira, R.: The JRA-25 Reanalysis, JMSJ, 85, 369-432, doi:10.2151/jmsj.85.369, 2007.

Overland, J. E., McNutt, S. L., Groves, J., Salo, S., Andreas, E. L., and Persson, P. O. G.: Regional sensible and radiative heat flux estimates for the winter Arctic during the Surface Heat Budget of the Arctic Ocean (SHEBA) experiment, J. Geophys. Res., 105, 14093-14102, doi:10.1029/1999JC000010, 2000.

Parkinson, C. L., Rind, D., Healy, R. J., and Martinson, D. G.: The Impact of Sea Ice Concentration Accuracies on Climate Model Simulations with the GISS GCM, J. Clim., 14, 2606-2623, doi:10.1175/1520-0442(2001)014;2606:TIOSIC $\dot{i} 2.0$. CO;2, 2001.

Persson, P. O. G., Fairall, C. W., Andreas, E. L., Guest, P. S., and Perovich, D. K.: Measurements near the Atmospheric Surface Flux Group tower at SHEBA: Near-surface conditions and surface energy budget, J. Geophys. Res., 107, 8045, doi:10.1029/2000JC000705, 1992.

Pielke, R. A.: Mesoscale Meteorological Modeling, chap. 7. Parameterization-Averaged Subgrid-Scale Fluxes, Academic Press, 2002.

Raddatz, R. L., Asplin, M. G., Candlish, L., and Barber, D. G.: General Characteristics of the Atmospheric Boundary Layer Over a Flaw Lead Polynya Region in Winter and Spring, Bound. Layer Met., 138, 321-335, doi:10.1007/s10546-010-9557-1, 2011.

Rigor, I., Colony, R., and Martin, S.: Variations in Surface Air Temperature Observations in the Arctic, 1979-1997, J. Clim., 13, 896-914, doi:10.1175/1520-0442, 2000.

Ruffieux, D., Persson, P. O. G., Fairall, C. W., and Wolfe, D. E.: Ice pack and lead surface energy budgets during LEADEX 1992, J. Geophys. Res., 100, 4593-4612, doi:10.1029/94JC02485, 1995. 
Shokr, M. and Kaleschke, L.: Impact of surface conditions on thin sea ice concentration estimate from passive microwave observations, Remote Sens. Environ., 121, 36-50, doi:10.1016/j.rse.2012.01.005, 2012.

Spreen, G., Kaleschke, L., and Heygster, G.: Sea ice remote sensing using AMSR-E 89-GHz channels, J. Geophys. Res., 113, C02S03, doi:10.1029/2005JC003384, 2008.

Stössel, A. and Claussen, M.: On the momentum forcing of a large-scale sea-ice model, Clim. Dyn., 9, 71-80, doi:10.1007/BF00210010, 1993.

Tisler, P., Vihma, T., Müller, G., and Brümmer, B.: Modelling of warm-air advection over Arctic sea ice, Tellus A, 60, 775-788, doi:10.3402/tellusa.v60i4.15301, 2008.

Tjernström, M. and Graversen, R. G.: The vertical structure of the lower Arctic troposphere analysed from observations and the ERA-40 reanalysis, Q. J. R. Meteorol. Soc., 135, 431-443, doi:10.1002/qj.380, 2009

Valkonen, T., Vihma, T., and Doble, M.: Mesoscale Modeling of the Atmosphere over Antarctic Sea Ice: A LateAutumn Case Study, Mon. Wea. Rev., 136, 1457-1474, doi:10.1175/2007MWR2242.1, 2008 .
Vihma, T. and Pirazzini, R.: On the factors controlling the snow surface and 2-m air temperatures over the Arctic sea ice in winter, Bound. Layer Met., 1117, 73-90, doi:10.1007/s10546-0045938-7, 2005.

Vihma, T., Hartmann, J., and Lüpkes, C.: A case study of an onice air flow over the Arctic marginal sea ice zone, Bound. Layer Met., 107, 189-217, doi:10.1023/A:1021599601948, 2003.

Vihma, T., Jaagus, J., Jakobson, E., and Palo, T.: Meteorological conditions in the Arctic Ocean in spring and summer 2007 as recorded on the drifting ice station Tara, Geophys. Res. Lett., 35, L18706, doi:10.1029/2008GL034681, 2008.

von Storch, H. and Zwiers, F. W.: Statistical Analysis in Climate Research, chap. 8 Regression, Cambridge University Press, UK, 1999.

White, P. W. E.: IFS documentation CY31r1: Part IV physical processes, http://www.ecmwf.int/research/ifsdocs/, 2006. 